\title{
Ideários da Educação Feminina na Primeira República Brasileira*
}

\author{
Renata Patricia Forain de Valentim** \\ Renata Dahwache Martins*** \\ Mariana Martelo Rodrigues****
}

\section{Resumo}

Partindo das propostas políticas e científicas que nortearam os caminhos da Primeira República brasileira, duas questões interrelacionadas se projetaram nesta pesquisa: resgatar as ideias básicas relacionadas à educação e à instrução da mulher, que começavam a se institucionalizar no Rio de Janeiro, $e$ compreender os diferentes graus de adesão desse ideário pedagógico às formulações normatizadoras, higiênicas $e$ eugênicas, que construíram o discurso hegemônico no período.

Palavras-chave: História das Mulheres, Eugenia, Higienismo, Primeira República.

* Recebido em 26 de agosto de 2017, publicado em 20 de agosto de 2019.

** Professora do Departamento de Psicologia Social e Institucional da Universidade do Estado do Rio de Janeiro, Rio de Janeiro, RJ, Brasil. renatapfvalentim@gmail.com / http://orcid.org/0000-0001-6272-0693

*** Psicóloga graduada pela Universidade do Estado do Rio de Janeiro e especializanda do programa de Psicologia Clínico Institucional do Instituto de Psicologia da UERJ, na modalidade residência hospitalar, Rio de Janeiro, RJ, Brasil. rdahwache@gmail.com / https://orcid.org/0000-0001-9634-1579

**** Psicóloga graduada pela Universidade do Estado do Rio de Janeiro , aluna do Estágio Multiprofissional em Saúde Mental em Nível de Residência do Hospital Psiquiátrico de Jurujuba e especializanda em Psicanálise e Saúde Mental pela Universidade Federal Fluminense, Niterói, RJ, Brasil. mariana.martelo@gmail.com / https://orcid.org/0000-0001-5587-6278 
Ideologies of Female Education in the First Brazilian Republic

\begin{abstract}
Starting from the political and scientific proposals that guided the institutional paths of the first Brazilian republic, two interrelated issues were projected in this research: to rescue the basic ideas related to education and instruction of Brazilian women, who became institutionalized in Rio de Janeiro; and to understand the different degrees of adherence of this pedagogical ideology to the normative, hygienic and eugenic formulations that have shaped the hegemonic discourse in the period.
\end{abstract}

Keywords: History of Women, Eugenic, Hygienic, First Brazilian Republic. 


\section{Introdução}

A escrita de uma história das mulheres há muito tempo deixou de ser identificada a partir de uma experiência única $e$ original. Se a sua emergência pode ser localizada no século XIX europeu (Fraisse; Perrot, 1991), sua presença em outros lugares ou momentos demonstra-se intrinsecamente relacionada às condições singulares da modernidade nas diferentes culturas, nas diversas construções de planos de interioridade reflexiva e em suas práticas sociais correspondentes.

Além de abrir a possibilidade de uma autonarrativa, o período moderno também foi o início da luta feminina pela conquista dos almejados ideais burgueses de igualdade $e$ liberdade, até então restritos a poucas categorias de "iguais". A arquitetura republicana compreendia apenas os "direitos do homem e do cidadão", em uma forma enunciativa na qual a pretensa universalidade funcionava mais como um marco de exclusão, alijando todos aqueles que, como as mulheres, não estavam incluídos nos critérios de verdadeiros "cidadãos da república" (Carvalho, 1990). Ainda assim, pode-se dizer que características desse período, tais como a laicização dos costumes, a organização social cada vez mais urbanizada e a industrialização ávida por mão de obra barata, acabaram por colaborar indiretamente para que se estabelecessem as lutas por instrução, trabalho assalariado e autonomia civil e política (Fraisse; Perrot, 1991), transformando progressivamente as relações entre homens e mulheres e instituindo outros lugares de enunciação e demanda.

No caso brasileiro - e de modo mais específico, em sua capital, a cidade do Rio de Janeiro - a chegada dos ideários modernistas entre o final do século XIX e princípio do XX, consistirá no abandono progressivo de sua feição imperial, rural e escravocrata, e a adoção de uma organização republicana, urbana $e$ industrializada. A busca era por instrumentos institucionais, que funcionassem para a superação do que era encarado pelos intelectuais brasileiros daquele momento como um "atraso" 
histórico. Tal descompasso era sentido como uma defasagem original em relação às matrizes europeias e atribuído por alguns, como Oliveira Viana, Ślvio Romero, Nina Rodrigues ou Euclides da Cunha, à sua população miscigenada.

As tentativas de modernização do espaço não se traduziram de forma imediata na melhoria das condições sociais da população em geral, muito menos nas condições em que viviam as mulheres. Porém ela abre, ainda que de forma tortuosa, novas possibilidades com relação à educação feminina, que agora terá uma função na ordem republicana e servirá aos projetos e ideais de modernização. No ideário republicano que começa a se institucionalizar, as mulheres serão as agentes dessa transformação, as maiores responsáveis pela difusão dos preceitos normativos, higiênicos, e as grandes mediadoras entre o poder público e a população em geral.

É consenso que o pensamento higienista brasileiro transcendeu as medidas sanitárias e cuidados elementares sobre a higiene do indivíduo e da população em geral (Boarini, 2003; Schwarcz, 2012; Wanderbroock Júnior; Boarini, 2007). Embora a cidade do Rio de Janeiro nesse período fosse conhecida pela insalubridade $e$ precariedade infraestrutural que atingia todos democraticamente, as políticas sanitaristas implementadas não atingiram de forma equitativa a população. De modo geral, foram orientações exclusoras, com forte apelo ao indivíduo e à hereditariedade como princípios de sustentação de uma nação saudável. Critérios que certamente não beneficiavam a massa de população negra ou miscigenada, recém-alforriada ou vinda do interior, que habitava os precários cortiços do centro da capital. Com a justificativa de promover o bom gene, a boa raça, o higienismo associou-se ao Estado e conferiu às ações do poder público um caráter técnico e científico que as legitimava. Sob essa perspectiva, qualquer coisa que se assemelhasse com uma deformação, desarmonia ou degeneração do "organismo social" idealizado seria motivo de intervenção normatizadora por parte das instituições republicanas que começavam a se construir. 
Partindo destas primeiras questões, duas expectativas em relação ao tema se projetaram nesta pesquisa. A primeira foi a de resgatar parte desse ideário relativo a educação $e$ instrução da mulher brasileira, que se institucionaliza nas primeiras décadas do século $\mathrm{XX}$ no Rio e Janeiro; perceber o que era difundido, tanto no ensino da Escola Normal do Distrito Federal, quanto nos discursos considerados mais libertários, da Federação Brasileira pelo Progresso Feminino e em seus ideais feministas sobre educação.

A segunda, diretamente ligada à primeira, foi investigar as duas propostas educativas que se colocam para o feminino em seu diálogo com o cenário cultural, social e político da cidade do Rio de Janeiro na Primeira República, aqui representado pela Liga Brasileira de Higiene Mental. Segundo Dias (2011), esta instituição da sociedade civil, considerada de utilidade pública, foi fundada no Rio de Janeiro em 1923, pelo psiquiatra Gustavo Riedel, e era composta pela elite da psiquiatria brasileira, além de outros profissionais como juristas e educadores. Inicialmente, seu objetivo era a melhora do atendimento psiquiátrico brasileiro e sua afinação com as discussões mais modernas acerca das doenças mentais. Ainda segundo Dias, a partir de 1926 as atividades da Liga se ampliam, extrapolam seus objetivos iniciais e passam a ter como finalidade a prevenção eugênica e a educação higiênica da população.

Com a análise desse diálogo, espera-se compreender os diferentes graus de adesão do ideário pedagógico que era destinado às mulheres às formulações normatizadoras, higiênicas $e$ eugênicas, que formataram o discurso científico acerca do feminino durante o período. Desta forma, inserindo a emergência desses ideais em uma perspectiva discursiva mais ampla, adequada ao conjunto de instrumentos de regulação social que precisou ser construído (ou reconstruído) após a crise institucional do segundo reinado.

A hipótese é a de que, durante a Primeira República brasileira, essas ideias modernizadoras do espaço urbano, que se imiscuíam aos ideais de educação e instrução da mulher brasileira, 
foram instrumentos que deveriam representar uma nova ordenação social e política, e que prometiam uma verdadeira respública". No entanto, acabaram na forma de um "novo racismo científico", que elegia arbitrariamente um conjunto de sinais para "definir a inferioridade e a falta de civilização" da população brasileira (Schwarcz, 2012:21).

Como instrumento de análise discursiva foi utilizado o conceito bakhtiniano de Dialogicidade (Charaudeau; Maingueneau, 2004), que foi a chave de leitura que possibilitou relacionar a Escola Normal e a Federação Brasileira para o Progresso Feminino a outros enunciados que lhes eram contemporâneos, como o da Liga Brasileira de Higiene Mental.

Como já mencionado, o plano de dialogicidade a ser estabelecido e analisado será o da relação entre o discurso acerca da educação feminina, que começava a se institucionalizar, e o discurso científico/republicano hegemônico que naquele momento também se instituía. Diálogos de ruptura (ou em vias de) com as relações verticalizadas da Monarquia e do patriarcado, porém, paradoxalmente relacionados ao estabelecimento de novas ordenações discriminatórias, baseadas agora no ideário eugenista e higienista. (Schwarcz, 2012).

\section{A Escola Normal do Distrito Federal}

Destinadas à formação de professores, as escolas normais tiveram seu processo de construção iniciado ainda no século XIX. Entre 1830 e 1880 foram fundadas as escolas de Niterói, Minas, Ouro Preto, Bahia, Pará e São Paulo, entre outras. Estas primeiras escolas, entretanto, funcionariam de modo intermitente até o final do Império, sendo abertas e fechadas várias vezes (Antunes, 2001).

No Rio de janeiro, a escola normal surge inicialmente como "Escola Normal da Corte", em decreto assinado pelo imperador Pedro Segundo, em 1876. Sua forma institucional definitiva,

1 Expressão latina que é a origem da palavra república. Significa coisa pública, do povo (Cunha, 2013). 
entretanto, demora muitos anos para se estabelecer. Segundo Acácio (2006), a dificuldade para seu estabelecimento pode ser atribuída às inúmeras falhas estruturais, como a falta de um prédio próprio, ou mesmo às questões pedagógicas não resolvidas, como a indefinição acerca da duração do curso ou a extensão de seu currículo "enciclopédico".

De qualquer modo, a Escola Normal da Corte já traz alguns elementos que serão reforçados a partir da proclamação da República, quando então ela passa a ser a Escola Normal do Distrito Federal. Ainda segundo Acácio (2006), essas marcas devem-se principalmente à direção positivista do militar e estadista Benjamin Constant, que sempre pretendeu constituir um ensino público, laico, voltado para a formação de professores $e$ professoras da instrução primária, que progressivamente deixará sua tendência humanista clássica, passando a absorver a tendência cientificista que dava seus primeiros passos na Europa e na América do Norte (Antunes, 2001).

Com o advento da República, em 1889, a Escola Normal sofre uma profunda reformulação curricular que implantará em definitivo a ideia de uma educação para ambos os sexos, bem como a obrigatoriedade do método intuitivo como procedimento didático da escola laica, a padronização nas condutas e a preocupação "científica" com as condições higiênicas e de moralidade dos lugares de ensino (Brasil, 1890:1).

Somente em 1901 caracteriza-se o magistério primário como profissão feminina. Nessa época, as portas das escolas normais já estão inteiramente abertas às mulheres, que passam a ser uma presença dominante no ensino primário (Acácio, 2006). Como já mencionado, tratava-se de uma profissão que não ofereceria risco à moral dominante, por estar intimamente vinculada à maternidade e àquilo que se imaginava como um dom naturalmente relacionado às mulheres. Segundo Louro (2002), era uma profissão que se adaptava também à laicidade exigida pela moral republicana, que incorporava as novidades científicas trazidas pelas disciplinas de psicologia, puericultura ou higiene, $e$ 
que paulatinamente, ao longo das primeiras décadas do século $\mathrm{XX}$, passam a integrar o currículo dos cursos.

$\mathrm{O}$ fato de o magistério tornar-se progressivamente uma profissão feminina relacionava-se também à variedade de oportunidades mais rentáveis que se abriam para os homens dentro do processo de urbanização $e$ industrialização, relegando às mulheres as profissões até então menos reconhecidas, como a docência (Louro, 2002). Mesmo assim, a abertura dessa pequena janela àquelas que estavam restritas unicamente ao lar ou à igreja não se faz de forma unânime, nem sem resistências ou críticas. Para alguns, a presença da mulher na atividade docente parecia um completo desvario, porque iria delegar às mulheres, tidas como despreparadas e infantilizadas, uma tarefa central como a educação das crianças (Louro, 2002).

Segundo Louro (2002), reconhecidamente frágil, a mulher precisava ser protegida, controlada. Toda e qualquer atividade fora do espaço doméstico representava um risco e deveria ser exercida "de modo a não as afastar da vida familiar, dos deveres domésticos, da alegria da maternidade, da pureza do lar" (Louro, 2002:453). As normalistas, que se projetavam para além dos espaços tradicionais, precisavam ser monitoradas, construindo uma concepção do trabalho fora de casa como ocupação passageira, que deveria ser abandonada sempre que se impusessem os papéis de esposa e mãe.

Dizia-se, ainda, que o magistério era próprio para mulheres porque era um trabalho de "um só turno", o que permitia que elas atendessem suas "obrigações domésticas" no outro período. Tal característica se constituiria em mais um argumento para justificar o salário reduzido - supostamente, um "salário complementar" (Louro, 2002:453).

Seja como for, progressivamente a Escola Normal se torna um curso de e para mulheres. Segundo Freire (2011:241), uma formação na qual a abertura profissional não supera os valores tradicionalmente relacionados ao feminino, tais como "dedicação- 
disponibilidade", "humildade-submissão", ou "abnegaçãosacrifício".

De forma ambivalente, nesse cenário de mudanças que se constrói, a representação da mulher se equilibrará (ou dividirá) sempre entre dois polos. No primeiro deles, a possibilidade de formação intelectual, de atuação profissional e aquisição de um espaço público até então inédito. No segundo, o sempre presente culto à domesticidade como forma de valorização conservadora das funções usualmente reconhecidas como femininas. Em ambos, a responsabilização da mulher pela reprodução dos valores morais e pela manutenção do bem estar familiar, saudável, em seu mais amplo sentido. Argumentos normatizadores, higiênicos, que defendem a vida privada e o amor materno como elementos basilares do desenvolvimento físico e emocional daqueles que serão os futuros cidadãos da república.

\section{A Federação Brasileira pelo Progresso Feminino (FBPF)}

Fundada em 19 de agosto de 1922, no Rio de Janeiro, a Federação Brasileira pelo Progresso Feminino é uma referência do movimento feminista brasileiro da primeira metade do século $\mathrm{XX}$, que tinha por objetivo principal promover a educação das mulheres, elevando seu nível de instrução, mas não só isso. Fundada no esteio da primeira Conferência Pan-americana de Mulheres, que ocorrera nos Estados Unidos nesse mesmo ano, a Federação também lutava pelo direito ao voto e almejava ainda fomentar discussões no âmbito profissional, fosse orientando as mulheres na escolha de sua profissão, fosse lutando pelos direitos já garantidos pela constituição ou auxiliando suas iniciativas $e$ obtendo garantias legais para o seu trabalho.

Sua história acompanha a disseminação das discussões acerca do lugar que deveria ser ocupado pelo feminino nas novas categorizações sociais definidas pelo Estado republicano. Seu embrião foi a Liga para a Emancipação Intelectual da Mulher, fundada em 1919, por Bertha Lutz e Maria Lacerda de Moura, posteriormente denominada Liga pelo Progresso feminino. $\mathrm{Na}$ 
expansão das ideias feministas, que se difundiam através da Liga $e$ estimulavam a organização feminina em outros estados brasileiros, formou-se então a Federação das Ligas pelo Progresso Feminino.

Por diferenças políticas, Maria Lacerda de Moura não participa da fundação da Federação, embora tenha mantido com Bertha Lutz uma relação afetuosa e igualmente comprometida com as lutas feministas (Martins; Costa, 2016). Enquanto Bertha Lutz prioriza um embate menos radicalizado, reivindicando a ampliação dos direitos políticos e legais, Maria Lacerda buscava uma aproximação mais efetiva das classes trabalhadoras, unindose logo em seguida ao movimento anarquista.

Em 1922, após a participação de Bertha Lutz como delegada oficial do Brasil na Primeira Conferência Pan-americana de Mulheres, a Federação das Ligas torna-se finalmente a Federação Brasileira pelo Progresso Feminino (FBPF), com sede na capital da República (Martins; Costa, 2016). Ainda em 22, a Federação, já consolidada, promove a I Conferência pelo Progresso Feminino, que teve como tese geral: "A colaboração da Liga pelo Progresso Feminino na educação da mulher, no bem social e aperfeiçoamentos humanos" (Bonato, 2005:134).

O surgimento da Federação no ano de 1922 é emblemático e faz parte de um conjunto de acontecimentos que começam a demarcar um novo momento para a sociedade brasileira. O país vivia um momento de grande ebulição cultural e política, que atingia todos os níveis de experiência social (Sevcenko, 2012). Momento de consolidação das formas capitalistas e tecnológicas e de tudo aquilo que a ela se relaciona, como a transformação de uma nação agrária em industrial, a migração em massa para os centros urbanos e a decorrente formação dos grandes conglomerados populacionais, caracterizados pelo abalo das tradições culturais e identitárias que balizavam as condutas sociais no meio rural.

Essa chegada das formas modernistas ao Brasil se traduziu, no campo cultural, na realização da Semana de Arte Moderna em 
São Paulo e, no campo político, no movimento tenentista do Rio de Janeiro e na fundação do Partido Comunista Brasileiro, em Niterói. Ainda em 1922 foi comemorado, com a abertura da Exposição Universal, o primeiro centenário da independência. Essa exposição, que já havia ocorrido antes em cidades como Londres e Paris, era considerada uma vitrine do progresso tecnológico e científico do país que a sediava. Segundo Bonato (2005), naquela que acontece em 1922, no Rio de Janeiro, a Conferência pelo Progresso Feminino vai usufruir de um espaço próprio para realizar algumas de suas atividades, em uma exibição que buscava dar visibilidade internacional para o Brasil como um país afinado às formas progressistas e libertárias da modernidade, entre as quais poderiam ser enquadradas as recentes e tímidas demandas feministas da Federação.

Na capital da República, a superação das feições coloniais que ainda predominavam, se materializa de modo concreto nas inúmeras transformações do espaço urbano e na progressiva expulsão das camadas populares para a periferia. $\mathrm{O}$ discurso acerca da higiene social que legitima as mudanças se dirige primordialmente à mulher e a toma como uma peça fundamental desse processo "civilizatório", difundindo-se através de artigos, propagandas na imprensa ou mesmo através de conferências, como as que ocorreram na sede da Liga Brasileira de Higiene Mental ou em outras entidades sociais, como na própria Federação Brasileira pelo Progresso Feminino (Bonato, 2005).

A escolarização das mulheres era vista pela Federação "como um problema vital, pois da solução dele dependeria o encaminhamento adequado dos demais problemas nacionais." (Nagle, 1974:109). Em sua organização, havia uma comissão específica para tratar do tema, a "Comissão de Educação e Instrução", criada com o objetivo de pensar a participação dessa entidade nas questões postas à educação feminina, tanto nas formas oficiais do sistema educacional, quanto na sociedade em geral. Seus temas eram, além da educação escolar das mulheres, a formação para o magistério primário, o exercício das profissões do 
comércio e ofícios e as funções consideradas "domésticas", essenciais para uma boa mãe de família, tais como medicina infantil, formação de valores familiares, higiene e criação dos filhos.

\section{A Mulher-Educadora $e$ a Liga Brasileira de Higiene Mental}

No contexto da Primeira República brasileira não havia uma elite política feminina, um grupo de mulheres que tivesse uma face "pública": "A mulher, se pública, era prostituta" (Carvalho, 1990:92). Neste cenário, a mulher-educadora era anônima, idealizada como um ser originalmente mais afetivo que racional, naturalmente adequada à promoção e à educação das crianças; aquela que conseguiria, através dos conhecimentos da higiene, "impor à família uma educação física, moral, intelectual e sexual, inspirada nos preceitos sanitários da época" (Castellani, 1988:32). Tarefa imposta em benefício da organização da cidade do Rio de Janeiro, que começava a concentrar um maior contingente populacional e a se direcionar para um modelo urbano mais consistente, afinado à institucionalização dos preceitos positivistas do recém-instalado Estado republicano e aos seus ideais de formação de uma raça brasileira "forte e saudável".

Cumpria-se assim uma dupla função. Por um lado, a presença do Estado tornava-se capilar, entrando de forma privilegiada no espaço familiar e privado através de cada cuidado $e$ ordenação dispensados pelas mulheres às suas famílias. Por outro, mantinha sob controle o espaço de constituição do feminino, restringindo-o ao ambiente privado da maternidade $e$ da família. Nesse sentido, são exemplares as palavras de PortoCarrero (1929:164), membro da Liga Brasileira de Higiene Mental:

Urge manter á mulher o seu sexo: orienta-la para profissões que correspondam devidamente ao seu impulso sexual; dar-lhe posição social que lhe torne desnecessaria a aspiração ao mando; educar os dois sexos para o amor, de modo a previnir o desejo da prostituição $e$ da 
promiscuidade; tornar a maternidade funcção pouco penosa, pela hygiene physica e mental. (Porto-Carrero, 1929:164)

Para o autor, o papel da mulher não deveria sair de sua vocação natural de ser mãe: "a funcção sexual da mulher não está completa sem a maternidade" (1929:164). A função social da mulher consistia em assumir a maternidade como um destino, inserido na ordem natural da espécie humana. Vincular a mulher às profissões da educação não seria desvalorizá-la socialmente, já que a ela, de forma naturalmente instituída, caberia a formação dos indivíduos sociais. E se a mãe na educação doméstica começava a instituir as regras morais, na escola, a professora completaria o ensinamento normativo e disciplinar (Mansanera, 2011).

A educação foi um dos grandes pretextos, ao lado do combate ao alcoolismo e do controle da imigração, para as intervenções da Liga Brasileira de Higiene Mental. Além da presença da disciplina "Higiene", obrigatória no currículo das Escolas Normais, os higienistas recomendavam, ainda, que fossem feitas campanhas educativas nas escolas primárias e secundárias. Essas campanhas deveriam reforçar a divulgação dos ensinamentos da puericultura, da higiene e dos processos de desenvolvimento infantil, com o objetivo de fornecer às alunas $e$ futuras professoras o conhecimento dos procedimentos obrigatórios para o cuidado e a atenção ao desenvolvimento da criança (Rocha, 2005).

A Liga Brasileira de Higiene Mental foi uma das entidades da sociedade civil criadas para estabelecer essa normatização das condutas. Fundada em 1923, no Rio de Janeiro, por Gustavo Riedel (Dias, 2011), seu foco era a prevenção eugênica e a educação higiênica da população. Segundo Dias (2011) e Seixas, Mota \& Zilbreman (2009), os ideais da Liga, ao mesmo tempo que expressavam uma ânsia pela modernização e pela construção de um "novo homem", condizente com os ideais de uma República recém-instituída, o faziam de forma conservadora e intolerante, 
que se confundia com "concepções e práticas racistas, xenófobas e autoritárias" (Dias, 2011:359). Os psiquiatras que a compunham (Henrique Roxo, Juliano Moreira, Renato Kehl, Júlio PortoCarrero, entre outros), influenciados pelo conceito de eugenia do fisiologista do século XIX, Francis Galton, e pela psiquiatria alemã que lhes era contemporânea, defendiam intervenções sociais na composição racial da sociedade brasileira,

seduzidos pela ideia de uma "ciência" que anunciava medidas decisivas para resolver o grave problema da composição racial do brasileiro, condição de possibilidade de construção da nação (Reis, 2000:136).

Segundo Mansanera (2011), os membros da liga pretendiam que as professoras utilizassem a higiene mental no domínio dos sentidos, da atenção, da imaginação, da memória, do pensamento, da vida afetiva e da vontade dos alunos. Seguindo a lógica do pensar higienista, a professora higiênica, informada sobre as fases de desenvolvimento da criança, poderia executar uma "profilaxia social" e interferir nas mudanças individuais do comportamento infantil, avaliando-o e classificando-o como próprio ou impróprio, desejável ou indesejável.

Com essas propostas, a liga funcionaria por 24 anos, de 1923 até 1947, com representantes em Pernambuco, São Paulo, Rio Grande do Sul e Minas Gerais, entre outros estados brasileiros (Dias, 2011). E, como se pode observar, durante esse período se estabeleceu um diálogo explícito com as mulheres, cobrando delas uma atuação "patriótica" na luta por uma sociedade "melhor", através de artigos e propagandas que eram veiculados na imprensa (Mansanera; Silva, 2000), ou mesmo em palestras e reuniões, como as que ocorreram na sede da Liga Brasileira de Higiene Mental e na própria Federação Brasileira pelo Progresso Feminino (Bonato, 2005). 
Considerações finais: dialogias

A dialogia, ou o meio pelo qual duas ou mais vozes podem interagir (Cunha; Sobrinho, 2013), foi um conceito elaborado pelo Círculo de Bakhtin para definir as relações que todos os enunciados mantêm com outros enunciados, sejam eles contemporâneos, precedentes ou futuros (Charaudeau; Maingueneau, 2004). Nessa concepção, a orientação dialógica seria a forma mais original e natural da linguagem, necessariamente desenvolvida em um meio social, onde o discurso de um falante encontra no discurso de outro seu prolongamento e seu sentido de ser.

O processo de interação entre os textos que acontece na dialogia é ininterrupto e caracteriza as produções de significação e sentido que serão elaborados por grupos sociais ao longo de sua história. Segundo Brait (2005), nessa interação intertextual não devem ser incluídas apenas as relações intersubjetivas. Também são dialógicas e atravessadas pelo componente social as significações que os sujeitos constroem na sua interação com o mundo. Assim como também tem um caráter dialógico a relação que os sujeitos estabelecem com a própria linguagem da qual se utilizam na comunicação, como por exemplo, o seu uso, função social ou o papel que ela ocupa dentro de uma determinada ideologia.

$\mathrm{O}$ prolongamento que um discurso encontra no outro, o entrelaçamento de orientações sociais e discurso implicarão em um caráter necessariamente fragmentado da linguagem, em que não se chocam ou discutem duas ou mais vozes monológicas, integrais, totais, mas vozes fracionadas, ora predominando uma $e$ ora outras (Bakhtin, 1929/2003). Combinações dissonantes, desarmoniosas, nas quais estão presentes elementos da interação social, que transcendem os aspectos formais do discurso, mas que são cruciais na atribuição do sentido, tais como a entonação, a previsão das réplicas ou os lugares sociais ocupados pelos falantes. 
O objetivo deste estudo foi a circunscrição e a comparação entre duas vertentes discursivas presentes na formação de um ideário acerca da educação feminina durante a Primeira República brasileira. No caso, a análise dos ideais presentes em uma formação institucionalizada, oferecida pela Escola Normal do Distrito Federal, e aqueles difundidos a partir de 1922 pela Federação Brasileira para o Progresso Feminino, uma instituição da sociedade civil.

Inicialmente, a proposta, partindo do conceito de dialogia proposto por Bakhtin, foi investigar como essas duas propostas educativas dialogavam com as formulações normatizadoras, higiênicas e eugênicas que formatavam o discurso científico $e$ ditavam as políticas públicas no período, como aquelas defendidas pela Liga Brasileira de Higiene Mental, também uma instituição da sociedade civil. A hipótese foi a de que, durante a primeira fase republicana brasileira, a modernização do Estado e suas políticas de exclusão social se imiscuíam aos ideais de educação e instrução da mulher, como instrumentos que Schwarcz (2012:21) vai denominar como "novo racismo científico", força de regulação social que começa a ser construída após a crise institucional do segundo reinado e a abolição da escravidão.

Mas, o que pode ser percebido é que não há uma relação ordenada, de causalidade, entre os ideários de educação feminina $e$ o higienismo. A interpretação que se propõe é a de que esses ideais de educação seriam em si mesmos dialógicos, polifônicos, produtos da interlocução entre os anseios de um feminismo nascente e as inúmeras forças políticas, capitalistas, industriais $e$ técnicas-científicas hegemônicas que precisavam reordenar seu território. Forças que convergem, de forma ininterrupta, dissonante e fragmentada, na institucionalização do feminino e em seus ideais de educação da mulher. Segundo Bakthin (1929/2003), uma forma de convergência que não produz algo neutro, idêntico a si mesmo, mas que realiza a multiplicidade essencial $e$ inalienável das falas e a sua diversidade. 
Essas dissonâncias e multiplicidades podem ser identificadas de modo claro nas propostas educativas da Escola Normal, que representam de forma ambivalente tanto o aprimoramento dos atributos supostamente "naturais", relacionados à maternidade $e$ ao cuidado, quanto o primeiro degrau em direção à ruptura com o naturalismo sexista, em um processo de emancipação profissional e acesso à educação formal. Podem ser identificadas, também na já mencionada adesão do feminismo ao discurso técnico-científico hegemônico, representado pela Liga Brasileira de Higiene Mental. Posição que acaba reforçando o discurso masculino conservador sobre as funções essenciais atribuídas às mulheres, principalmente aquelas que lhes designam o lugar da higiene social, da responsabilidade sobre a saúde física e moral da família e por extensão do tecido social. Essa percepção se intensifica no caso da Federação Brasileira pelo Progresso Feminino, que, embora expressasse em seus estatutos uma preocupação com a mulher trabalhadora, era integrada quase que exclusivamente por mulheres da alta classe média, que construíram um discurso feminista ameno, legalista, que não abalava as estruturas patriarcais $e$ se aproximava do discurso conservador de higienização do tecido urbano $e$ de institucionalização $e$ reordenação territorial das camadas populares.

A presença do discurso cientificista como única via de acesso às formas emancipadas do feminino une até mesmo as divergentes Bertha Lutz e Maria Lacerda de Moura. Embora esta última tenha se indignado com as condições de vida do proletariado paulista e decidido abandonar o discurso ameno $e$ reformista do grupo ligado à FBPF, permanece idealizando a fundação de uma universidade com núcleos em todo o país, não se limitando ao Rio de Janeiro, em que o ensino fosse racionalista e científico (Schumaher; Brazil, 2000). Moura acreditava ser possível, assim, desenvolver nas mulheres a capacidade de continuidade da luta pela emancipação e não postulava nenhuma observação crítica sobre a natureza do pensamento científico desenvolvido, 
nem sobre sua associação às diversas operações de exclusão social.

\section{Referências bibliográficas}

ACCÁCIO, Liéte Oliveira. Formando o professor primário: a Escola Normal e o Instituto de Educação do Rio de Janeiro. In: LOMBARDI, José Claudinei; SAVIANI, Demerval; NASCIMENTO, Maria Isabel Moura (org.). Navegando pela História da Educação Brasileira. Campinas, SP, Graf. FE, HISTEDBR, 2006, pp.1-25.

ANTUNes, Maria Aparecida Mitsuko. A Psicologia no Brasil. SP, Educ, 2001.

BAKHTIN, Mikhail. Problemas da poética de Dostoiévski. Rio de Janeiro, Forense Universitária, 2003 [1929].

BOARINI, Maria Lúcia. Higiene e raça como projetos: higienismo e eugenismo no Brasil. Maringá, EDUEM, 2003.

BONATO, Nailda Marinho da Costa. O Fundo Federação Brasileira pelo Progresso Feminino. Uma fonte múltipla para a história da educação das mulheres. Acervo, Rio de Janeiro, 2005, pp.131-146.

BRAIT, Beth. Bakhtin e a natureza constitutivamente dialógica da linguagem. In: BrAIT, Beth (org.). Bakhtin. Dialogismo e Construção do sentido. Campinas, Unicamp, 2005.

BRASIL. Câmara dos Deputados. Decreto n. 981. In: BRASIL, Decretos do Governo Provisório da República dos Estados Unidos do Brasil. Rio de Janeiro, 1890.

Carvalho, José Murilo de. A Formação das Almas: $O$ imaginário da república no Brasil. S.P., Cia das Letras, 1990.

CASTEllani, Lino. Educação física no Brasil: A história que não se conta. Campinas, Papirus, 1988.

Charaudeau, Patrick; Maingueneau, Dominique. Dicionário de Análise do Discurso. S.P., Contexto, 2004.

CunHA, Antônio. Geraldo da; SoBRINHO, Cláudio Mello. Dicionário Etimológico da língua portuguesa. RJ, Lexikon, 2013. 
DIAS, Rafael. Mendonça Liga Brasileira de Higiene Mental (LBHM) 1923-1947. In: VILELA, Ana Maria Jacó (org.). Dicionário Histórico de Instituições de Psicologia no Brasil. R.J, Imago, 2011, pp.358-360.

FRAISSE, Geneviève; PERROT, Michelle. Introdução: Ordens e liberdades. In: FraISSE, Geneviève; PERROT, Michelle. História das Mulheres. O século XIX. Porto, Afrontamento, 1991, pp.9-15.

FREIRE, Eleta de Carvalho. Mulher no magistério: uma história de embates entre espaço público e espaço privado. Revista Lugares de Educação. Bananeiras/PB, 2011, pp.239-256.

LOURO, Guacira Lopes. Mulheres na sala de aula. In: DEL PRIORE, Mary. História das Mulheres no Brasil. São Paulo, Editora Contexto, 2002, pp.443-481.

MANSANERA, Adriano Rodrigues. A história da Psicologia da Educação no Brasil: Os procedimentos higiênicos da mãe e da professora. Revista Lentes Pedagógicas, 2011, pp.63-85.

MANSANERA, Adriano Rodrigues; SILVA, Lúcia Cecília da. A Influência das ideias higienistas no desenvolvimento da psicologia no Brasil. Psicologia em Estudo, 2000, pp.115-137.

MARTINS, Ângela Maria Souza; CosTA, Nailda Marinho da. Movimento Feminista e Educação: cartas de Maria de Lacerda de Moura para Bertha Lutz (1920-1922). Revista Contemporânea de Educação, 2016, pp.211-229.

NAGLE, Jorge. Educação e sociedade na primeira república. S.P., EPU Edusp, 1974.

Porto-CARrero, Júlio. Educação sexual. R. J., ABHM, 1929.

REIS, José Roberto Franco. "De pequenino é que se torce o pepino": a infância nos programas eugênicos da Liga Brasileira de Higiene Mental. História, Ciências, Saúde, 2000, pp.135-157.

RochA, Heloísa Helena Pimenta. A educação sanitária como profissão feminina. cadernos pagu (24), Campinas, SP, Núcleo de Estudos de Gênero - Pagu/Unicamp, 2005, pp.69-104. 
SCHWARCZ, Lilia Maria. Introdução: as marcas do período. In: SCHWARCZ, Lília Maria. História do Brasil Nação: a abertura para o mundo. RJ, Objetiva, 2012, pp.19-34.

SeiXAS, André Augusto Anderson; MotA, André; Zilbreman, Mônica. A origem da Liga Brasileira de Higiene Mental e seu contexto histórico. Revista de Psiquiatria do Rio Grande do Sul (31), 2009, pp.82-82.

SEVCENKO, Nicolau. Introdução. O prelúdio republicano, astúcias da ordem e ilusões do progresso. In: SEVCENKO, Nicolau. História da Vida Privada no Brasil, vol.3. R.J., Cia das Letras, 2012.

WANDERBROOCK JUNIOR, Durval; BOARINI, Maria Lúcia. Educação higienista, contenção social: a estratégia da Liga Brasileira de Hygiene Mental na criação de uma educação sob medida (1914-1945). In: Anais da VII Jornada do HISTEDBR, Campo Grande, 2007. 